\title{
ANÁLISE DA VIABILIDADE DE IMPLANTAÇÃO DE UMA USINA DE RECICLAGEM DE PNEUS EM TEIXEIRA DE FREITAS - BA
}

\author{
Carolina Izabella Aparecida Ribeiro Andrade ${ }^{1}$ \\ Raildo Mota de Jesus ${ }^{2}$ \\ Jefferson de Oliveira Cruz ${ }^{3}$
}

\section{RESUMO}

Esta pesquisa tem como objetivo principal propor um modelo de usina de reciclagem como uma alternativa para a solução da problemática em relação ao gerenciamento dos pneus inservíveis no extremo sul da Bahia, contribuindo com a redução dos impactos ambientais e possibilitando um maior desenvolvimento social e econômico na região do extremo sul baiano. Com a pesquisa documental e bibliográfica, alinhada à pesquisa de campo e a empreendedores locais do segmento de logística reversa, e ao Departamento Estadual de Trânsito da Bahia, foi possível realizar um estudo de viabilidade para a instalação local de uma usina de reciclagem, indicando fatores condicionantes para o empreendimento. Assim foram estimados os custos envolvidos na implantação de uma usina, e a análise da viabilidade econômica do negócio.

Palavras-chave: Logística reversa. Pneus inservíveis. Recicladora

\section{ABSTRACT}

This research aims to propose a model of the recycling plant as an alternative to this problem, using management of scrap tires in southern Bahia, whose contribute to the reduction of environmental impacts and enable the further social and economical development in this region. With the documentary and bibliographic research, aligned with field research and local entrepreneurs of the reverse logistics segment, aligned to Bahia's Traffic Department, it was possible to conduct a feasibility study for the local installation of a recycling plant, indicating factors responsible for the project. Thus the costs involved in the implementation of a power plant, and the analysis of the economic viability of the business were estimated.

Keywords: Reverse logistics. Scrap tires. Recycler

\section{Introdução}

O descarte indiscriminado de pneus pós-consumo, quando dispostos de forma inadequada, causam danos irreversíveis ao meio ambiente, pois não são biodegradáveis, e seu tempo de decomposição ainda não é precisamente determinado. Eles ocupam muito espaço físico e são difíceis de comprimir, recolher e eliminar, tornando-se ideais para a reprodução do mosquito Aedes aegypti, conhecido popularmente como

\footnotetext{
${ }^{1}$ Universidade Estadual Santa Cruz. Mestrado em Desenvolvimento Regional e Meio Ambiente (UESC). Coordenadora do Curso de Engenharia de Produção, Faculdade do Sul da Bahia (FASB). Campus Soane Nazaré de Andrade (Salobrinho), Km 16, BR-415, BA, CEP: 45662-900. E-mail: carolina.andrade@ffassis.edu.br

${ }^{2}$ Universidade Estadual Santa Cruz. Doutorado em Química Analítica (UFBA). Coordenador do Programa de Pós-Graduação em Química (UESC). Campus Soane Nazaré de Andrade (Salobrinho), Km 16, BR-415, BA, CEP: 45662-900. E-mail: raildomota@gmail.com

${ }^{3}$ Universidade Estadual Santa Cruz. Mestrado em Desenvolvimento Regional e Meio Ambiente (UESC). Campus Soane Nazaré de Andrade (Salobrinho), Km 16, BR-415, BA, CEP: 45662-900. E-mail: joc0312@gmail.com
} 
"mosquito da dengue", causando mal à saúde humana (UNITED NATIONS ENVIRONMENTAL PROGRAMME, 2010). Embora no Brasil exista regulamentação ambiental voltada para esse problema, como a Lei $n^{\circ}$ 12.305/2010 (BRASIL, 2010), que instituiu a Política Nacional de Resíduos Sólidos, ela ainda demonstra ser pouco eficiente quando posta em prática na região do extremo sul da Bahia.

O Conselho Nacional de Meio Ambiente (CONAMA), através da Resolução ${ }^{\circ}$ 416 de 2009, determinou que os fabricantes de pneus com o peso unitário superior a dois quilos devem fazer a coleta e dar a destinação adequada desses itens quando se tornarem inservíveis (NOVICK; MARTIGNONI, 2000). Assim, tornou-se necessário buscar soluções para os problemas relacionados a esse passivo ambiental de modo a viabilizar sua destinação correta. Observa-se na reciclagem uma possível solução para a logística reversa dos pneus inservíveis, tanto em termos ambientais como em termos econômicos. Pois a borracha triturada, dos pneus inservíveis, pode ser usada como matéria-prima para diversos processos de reciclagem e reúso (STATE OF OHIO ENVIRONMENTAL PROTECTION AGENCY, 2007). O objetivo principal dessa pesquisa é analisar a viabilidade ambiental, social e econômica de uma usina de reciclagem como uma alternativa para a solução da problemática em relação ao gerenciamento dos pneus inservíveis no extremo sul da Bahia.

\section{0 gerenciamento dos pneus inservíveis e a legislação ambiental}

Os resíduos sólidos, quando acumulados de forma incorreta, são responsáveis diretos por impactos ambientais negativos de grandes proporções (MOTTA, 2008). A gestão correta desses resíduos é uma forma de solucionar o problema de poluição do meio ambiente que afeta também a saúde pública (XAVIER; CORREA, 2003). As principais formas de gestão desses resíduos resumem-se em reutilização, reciclagem, recuperação energética e disposição de forma adequada (NORTH DAKOTA DEPARTMENT OF HEALTH, 2011). O gerenciamento dos resíduos sólidos nas décadas de 1950 e 1960, segundo Cheung, Lee e Mckay (2007), resumia-se muitas vezes na prática da incineração, aumentando essa ação consideravelmente nos anos 1960 e 1970. Eram consideradas nessa prática várias vantagens, pois tinham a possibilidade de recuperar a energia do lixo em chamas e diminuíam de $80 \%$ a $90 \%$ seu volume, reduzindo, assim, a área necessária para a criação dos aterros. Demajorovic (1995) afirma que a relação entre os problemas ambientais e os resíduos sólidos vem 
acompanhado de um conhecimento crescente das implicações relacionadas aos impactos ambientais, causados pelo aumento do volume desses resíduos dispostos de forma inadequada.

No Brasil, a Lei n ${ }^{\circ}$ 12.305, de 2 de agosto de 2010 (BRASIL, 2010), instituiu a Política Nacional de Resíduos Sólidos como forma de direcionar e sancionar as diretrizes do gerenciamento dos resíduos sólidos e a responsabilidade dos geradores desses resíduos e do poder público. A lei também é clara ao obrigar os fabricantes, importadores, distribuidores e comerciantes (art. $33^{\circ}$ ) de pneus a implantar a logística reversa.

Em relação aos pneumáticos, como resíduos sólidos, em 1999, o Conselho Nacional do Meio Ambiente (CONAMA) aprovou a Resolução de n 258 (BRASIL, 1999). Essa resolução foi alterada pela Resolução no 301/2002 (BRASIL, 2002), e revogada pela Resolução CONAMA no 416/09 (BRASIL, 2009), atualmente em vigor. Esta é a que define as diretrizes sobre a prevenção da degradação do meio ambiente relacionada aos pneus inservíveis e dá as providências em relação a sua destinação adequada. De acordo com essa resolução, os fabricantes e importadores, articulados com distribuidores, revendedores e consumidores finais, deverão obedecer aos procedimentos para a coleta correta dos pneus inservíveis no país.

Alguns estudos desenvolvidos no Brasil abordaram o diagnóstico do gerenciamento da logística reversa dos pneus inservíveis em algumas regiões do país. A pesquisa desenvolvida por Aguiar e Furtado (2010), em Fortaleza, demonstrou que muitas vezes as revendedoras de pneus encaram a logística como um custo a mais para a empresa, e, mesmo com a lei obrigando a destinação adequada dos pneus usados, algumas revendas simplesmente ignoram as normas regulamentadoras. "[...] Ainda são muito grandes os problemas relacionados ao descarte dos pneus usados, com a criação das normas e dos órgãos fiscalizadores [...] ainda não existe por parte do poder público e órgão competentes uma forte campanha para a conscientização de todos envolvidos no processo" (AGUIAR; FURTADO, 2010, p. 13). A pesquisa de Spreafico (2012) intitulada Diagnóstico da logística reversa de pneus inservíveis na região Norte do Ceará também concluiu que existe grande desconhecimento em relação a destinação dos pneus inservíveis da região, e, com isso, a quantidade de pneus coletados é pequena. “[...] assim, muitos pneus inservíveis estão sendo usados como pneu de meia-vida, 
assim colocando em risco condutores, a população e o meio ambiente" (SPREAFICO, 2012, p. 1).

\section{Materiais e métodos}

Inicialmente foi feita uma pesquisa bibliográfica sobre a logística reversa dos pneus inservíveis, buscando informações sobre tecnologias utilizadas para a reciclagem desses pneus e sua destinação no Brasil. O diagnóstico do atual gerenciamento da cadeia de logística reversa dos pneus inservíveis foi feito através de visitas à Prefeitura Municipal da cidade, para conhecer as políticas públicas e as práticas de desenvolvimento sustentável em Teixeira de Freitas; foram feitas também visitas às Secretarias de Meio Ambiente e de Planejamento para uma pesquisa documental. Visitas feitas ao Aterro Sanitário da cidade contribuíram para conhecer como é feito o armazenamento dos pneus inservíveis que chegam até o local.

Através de uma análise bibliográfica e documental foi possível conhecer os pontos de coleta de pneus em Teixeira de Freitas, buscando informações de origem e destinação atual dos pneus inservíveis através de algumas associações de reciclagem. Por meio de uma observação não participativa em 23 pontos integrantes do setor de pneumáticos na região do extremo sul, foi possível conhecer como funciona a logística reversa e o mercado dos pneus inservíveis na região do extremo sul da Bahia.

Dados sobre localização dos pontos de coleta de pneus inservíveis na região foram obtidos através da ONG Reciclanip, principal instituição brasileira voltada à reciclagem e pesquisa de destinação de pneus inservíveis no país. Os dados relacionados à frota atual da região do extremo sul foram possíveis através de visitas ao Departamento Estadual de Trânsito da Bahia e ao site do órgão. Com a pesquisa documental e bibliográfica, alinhada à pesquisa de campo aos empreendedores locais do segmento de logística reversa, foi proposto um projeto fictício de uma usina de reciclagem de pneus e foi feito o estudo da sua viabilidade. Esta seria uma possível solução para a falta da coleta e destinação correta desses pneus, indicando fatores condicionantes para o empreendimento e retorno esperado. Assim foram estimados os custos envolvidos na implantação de uma usina, foram efetuados os cálculos do valor do empreendimento, do investimento necessário, das despesas envolvidas e a análise da matéria-prima disponível, conforme Cassarotto Filho (2002). Para análise da viabilidade 
econômica do negócio, foram utilizados os indicadores recomendados por Crepaldi (2006).

O problema de logística em relação aos pneus inservíveis se estende por todo o Brasil, mas este estudo será desenvolvido na região do extremo sul da Bahia, em Teixeira de Freitas. A escolha desse local de pesquisa se justifica porque Teixeira de Freitas apresenta a maior frota de veículos do extremo sul baiano (Tabela 1), o que a condiciona como maior produtora de pneus inservíveis na região. Teixeira de Freitas também é a mais populosa cidade do extremo sul da Bahia e a décima cidade com a maior população no estado, segundo dados do IBGE (2013), o que a coloca como uma cidade destaque na região do extremo sul.

\section{Resultados e discussão}

\subsection{Análise da frota atual de veículos na região do extremo sul}

Através de visitas ao Departamento Estadual de Trânsito da Bahia, foi possível obter os dados relacionados à frota atual da região do extremo sul.

Foi observado que Teixeira de Freitas, Eunápolis e Porto Seguro são as cidades que apresentam as maiores frotas da região do extremo sul da Bahia, sendo potenciais produtoras de pneus inservíveis, destacando-se Teixeira de Freitas, com quase 50 mil veículos cadastrados.

Segundo os fabricantes de pneus, um pneu pode durar em média de 45 mil a 55 mil quilômetros, mas em termos de anos essa informação é bem relativa, segundo os mesmos fabricantes. Um pneu pode chegar a dez anos sem ter seu desgaste total, mas para uma média em termos de segurança, leva-se em consideração cinco anos de uso. Assim, todos os cálculos desta pesquisa levarão em conta essa média de uso. Serão contabilizados os pneus de motocicletas, automóveis, caminhão e ônibus.

Para o cálculo da quantidade média de pneus inservíveis disponíveis no ano de 2014 (Tabela 1), levou-se em consideração o cálculo a seguir:

QPR (2014) = QAV - QAV4A

Em que:

QRP = Quantidade de pneus inservíveis em 2014. 
QAV = Somatório de veículos acumulados nos últimos 5 anos (2010 a 2014).

QAV4A = Somatório de veículos no último ano (2013).

Tabela 1 - Quantidade média de pneus inservíveis em 2014 no Extremo Sul da Bahia

\begin{tabular}{|c|c|}
\hline TIPO DE VEÍCULO & QUANTIDADE MÉDIA (unidade) \\
\hline Automóveis & 22.600 \\
\hline Caminhões & 4.653 \\
\hline Ônibus & 885 \\
\hline Motocicletas & 13.438 \\
\hline TOTAL & 41.576 \\
\hline
\end{tabular}

Através dos cálculos, obteve-se um panorama de que vários pneus são substituídos e necessitam de destinação correta.

Para conhecer o atual gerenciamento da cadeia de logística reversa dos pneus inservíveis na região do extremo sul da Bahia, foram feitas visitas em 23 pontos integrantes do setor de pneumáticos para a pesquisa de campo.

Dentre os 23 pontos do setor visitados, 11 eram borracharias e 12 eram revendedoras/reformadoras. Para a escolha desses pontos, levou-se em consideração a indicação feita por sujeitos que pertencem a esse segmento durante toda a pesquisa. Essa amostra se mostrou representativa, pois contém em proporção adequada todas as características qualitativas e quantitativas da população em estudo. Em todos os locais, foram feitas observações não participativas das seguintes variáveis:

- existência de incentivos para a destinação correta dos pneus inservíveis;

- se o local é ou não ponto de coleta de pneus inservíveis.

Em todos os 23 pontos pesquisados integrantes do setor de pneumáticos não havia qualquer controle de movimentação sobre a logística reversa dos pneus inservíveis, muitos sequer recebiam pneus inservíveis, e os que eram trocados eram encaminhados para o lixo comum, não cumprindo o que é estabelecido pelo art. $9^{\circ}$ da Resolução 416/2009 do CONAMA, que diz:

Os estabelecimentos de comercialização de pneus são obrigados, no ato da troca de um pneu usado por um pneu novo ou reformado, a receber e armazenar temporariamente os pneus usados entregues pelo consumidor, sem qualquer tipo de ônus para este, adotando procedimentos de controle que identifiquem a sua origem e destino. (CONAMA, p. 4) 


\subsection{O gerenciamento dos pneus inservíveis em Teixeira de Freitas}

A Prefeitura Municipal de Teixeira de Freitas possui um convênio com a RECICLANIP, pelo qual a empresa se responsabiliza por toda a gestão logística de retirada dos pneus inservíveis do ponto de coleta cadastrado e pela destinação ambientalmente adequada desse material em empresas licenciadas pelos órgãos ambientais e homologadas pelo IBAMA, porém a logística não acontece de forma eficiente. Em Teixeira de Freitas, todos os pneus que chegam ao aterro sanitário da cidade são colocados em um local específico, porém, aberto sem cobertura. Foi observado durante toda a pesquisa que as borracharias da cidade não procuram enviar os pneus inservíveis ao aterro, a maioria descarta no meio ambiente, coloca no lixo comum ou vende para uma revendedora de pneus que possui uma pequena trituradora de pneus no galpão da revenda. Essa revendedora está cadastrada no IBAMA como um dos 41 pontos de coleta da Bahia, sendo um dos quatro pontos cadastrados na região do extremo sul, dois em Teixeira de Freitas, um em Eunápolis e um em Porto Seguro.

O ponto cadastrado em Eunápolis é uma loja de autopeças que vende pneus, porém não recolhe os inservíveis. No ponto de coleta em Porto Seguro, ocorre o mesmo, eles só revendem. Dos dois pontos cadastrados em Teixeira de Freitas informados pelo IBAMA (2013), no Relatório de Pneumáticos, no da Rodovia BR101 funciona a pequena recicladora de pneus, que transforma os pneus inservíveis em raspas (pó). O processo é simples, eles apenas trituram os pneus inservíveis e vendem as lascas para empresas interessadas. O produto final tem que passar por outro tratamento, uma vez que parte do ferro está misturado ao produto. Segundo dados da empresa, a cada dois meses são produzidos cerca de 10 mil quilos de raspas. O único comprador atualmente é uma usina de reciclagem em São Paulo. A quantidade de pontos de coleta cadastrados pela Reciclanip é diferente em relação aos pontos cadastrados pelo IBAMA, enquanto o Relatório de Pneumáticos cadastrados pelo IBAMA apresenta 41 pontos, a Reciclanip apresenta 20 pontos de coleta, sendo somente duas na região do extremo sul: um localizado em Teixeira de Freitas e um em Porto Seguro.

Ao contatar o ponto de coleta em Teixeira de Freitas, foi identificado como sendo o número da Vigilância Epidemiológica da cidade, e, segundo informado, lá não é ponto de coleta, e o único órgão responsável pelo recolhimento que seria a Secretaria do Meio Ambiente não está mais fazendo esse serviço. Nas Secretarias de Meio Ambiente 
e Prefeituras das cidades vizinhas à Teixeira de Freitas, verificou-se que não há responsáveis envolvidos com essa questão ambiental. Isso se deve principalmente pela falta de atuação do poder público. As prefeituras não têm programas ou políticas de recolhimento dos pneus. Nessas cidades não existem pontos de coleta oficiais, assim, as borracharias e os pontos de revenda se tornam responsáveis pelo recolhimento dos pneus usados. Isso contribui muito para a incorreta destinação dos pneus, uma vez que passam a ser descartados no lixo comum e o que chega até as borracharias e pontos de revenda não tem a destinação final correta em relação às questões ambientais.

Foi sugerido como possível solução para o problema dos pneus inservíveis na região do extremo sul baiano a instalação de uma usina de reciclagem. Essa sugestão foi feita com base na pesquisa de Libera et al. (2012), na qual a implantação de uma usina recicladora de pneus inservíveis na cidade de Santa Maria constitui-se como uma ótima alternativa em termos ambientais.

\subsection{Proposta de reciclagem dos pneus inservíveis em Teixeira de Freitas}

\subsubsection{Viabilidade econômica da recicladora de pneus inservíveis}

Os critérios operacionais da recicladora foram dispostos e propostos a partir dos dados obtidos junto a uma empresa especializada em máquinas de reciclagem, localizada na cidade de São Paulo. A localização do empreendimento seria no Distrito Industrial de Teixeira de Freitas, com localização privilegiada à margem esquerda da Br-101, no km 884, sentido Vitória do Espírito Santo, estando a 8,2 km da Rodovia BA290, facilitando a logística de chegada da matéria-prima e da saída dos produtos reciclados, diminuindo assim os custos associados ao transporte. $\mathrm{O}$ galpão industrial necessário para a instalação da recicladora seria de aproximadamente $700 \mathrm{~m}^{2}$, tamanho ideal para um empreendimento desse ramo, segundo a empresa onde foram orçados todos os equipamentos, com setor administrativo acoplado e banheiro, executado com fechamento lateral em blocos de concreto e estrutura metálica com telhas de fibrocimento e piso de alta resistência. O custo estimado para a construção do galpão é de $\mathrm{R} \$$ 749.070,00, sendo $\mathrm{R} \$$ 549.668,00 referentes a materiais e $\mathrm{R} \$ 199.402,00$ referentes à mão de obra. Esses custos foram estimados pelo CUPE - Custo Unitário PINI de Edificações (2013), tendo como mês de referência dezembro de 2013; não foi considerada a taxa de administração da construtora que varia de $10 \%$ a $20 \%$, em média. Esse é um valor médio de mercado. 
O setor administrativo será mobiliado com duas mesas de escritório com as respectivas cadeiras, mais três cadeiras de atendimento e um banco de espera, três armários em aço, dois computadores, uma impressora multifuncional, dois aparelhos de telefone, um bebedouro refrigerado com galão de água e um aparelho de ar condicionado. Os equipamentos mencionados foram orçados em empresas do ramo, localizadas em Teixeira de Freitas. O custo total encontrado foi de R\$13.364,15. É importante que seja colocado um sistema de segurança. $\mathrm{O}$ orçamento pesquisado foi feito por uma empresa de equipamentos de segurança, também em Teixeira de Freitas, chegando a um custo total de $\mathrm{R} \$ 1.200,00$. Na Tabela 2, é possível observar uma síntese dos custos referentes ao projeto de implantação da recicladora.

Tabela 2 - Síntese dos custos referentes ao projeto de implantação

\begin{tabular}{lr}
\hline DESCRIÇÃO & \multicolumn{1}{c}{ VALORES (R\$) } \\
\hline Galpão industrial de $700 \mathrm{~m}^{2}$ & $749.070,00$ \\
Mobiliário do escritório & $13.364,15$ \\
Sistema de segurança & $1.200,00$ \\
Equipamentos e máquinas & $870.000,00$ \\
\hline TOTAL & $1.633 .634,15$ \\
\hline
\end{tabular}

Fonte: elaborada pelos autores com base nos dados da pesquisa (2014).

Segundo a empresa que fornecerá os equipamentos e maquinários da recicladora, para um bom funcionamento do processo seriam necessários um operador direto e dois auxiliares para os equipamentos, por turno de trabalho. $\mathrm{O}$ investimento estimado em equipamentos e máquinas é de $\mathrm{R} \$ 870.000,00$. A instalação e o treinamento contarão com uma equipe de dois técnicos e um engenheiro, ficando tudo por conta da empresa. É necessário um prazo médio de 15 dias para toda a instalação do equipamento.

Segundo informações da empresa responsável pelo fornecimento do maquinário, os processos de reciclagem dos pneus acontecem em quatro principais etapas:

ETAPA 1: Trituração dos pneus para reduzir o volume. Nessa etapa, os pneus passam por um equipamento de trituração, com uma esteira alimentadora automática.

ETAPA 2: Moagem. Depois de triturado, os pedaços de pneus são direcionados a um segundo equipamento que reduz seu volume significativamente, normalmente para menos de $20 \mathrm{~mm}$.

ETAPA 3: Remoção do metal. Os pedaços de pneus são carregados para uma mesa vibratória que dispersa o material. Uma cinta de remoção de metal fica situada 
sobre ela. A cinta tem um ímã permanente que atrai os filamentos de aço harmônico, separando-as da borracha durante a fase prévia da moenda, e os envia para o armazenamento em um recipiente de coleta.

ETAPA 4: O processo para limpar a borracha e remover o aço e os resíduos de fibra têxteis são altamente sofisticados e se dão em duas fases. Cabe ressaltar que a limpeza final se dá através de dois separadores densitométricos que limpam totalmente o granulado de borracha da fibra têxtil.

Para a implantação desse projeto, pode-se pensar em um financiamento da recicladora, caso seja necessário, pois existe a possibilidade de financiamentos em instituições de crédito que apoiam a realização de investimentos em projetos, concedendo crédito para o financiamento de máquinas e equipamentos, e também existem incentivos fiscais oferecidos pelo Estado e por alguns municípios favorecendo o desenvolvimento da indústria na região. Porém, não foi intenção deste estudo pesquisar quais linhas de crédito são disponíveis, ou quais incentivos são disponibilizados, por isso, não se tem explanação detalhada desses processos.

Foram calculadas as despesas (média/mensal) com telefone, energia e água (Tabela 3). Essas despesas foram obtidas por uma média feita levando em consideração o ano de 2013, em uma empresa que atua no mesmo ramo no estado de São Paulo. A pedido da empresa, ela não será identificada.

Tabela 3 - Despesas médias com água, energia e telefone

\begin{tabular}{cc}
\hline DESCRIÇÃO & VALOR MÉDIO/MÊS (R\$) \\
\hline Água & 115,78 \\
Energia & $2.366,57$ \\
Telefone & 332,98 \\
\hline TOTAL & $2.815,33$ \\
\hline Fonte: elaborada pelos autores com base nos dados da pesquisa (2014).
\end{tabular}

Os salários médios mensais a serem pagos estão descritos na Tabela 4. Foram incluídos 31,44\% de encargos trabalhistas, correspondentes a férias $(11,11 \%), 13^{\circ}$ salário $(8,33 \%)$, FGTS (8\%) e provisão de multa para rescisão (4\%). 
Tabela 4 - Salários médios a serem pagos

\begin{tabular}{lccc}
\hline FUNÇÃO & $\begin{array}{c}\text { NÚMERO DE } \\
\text { FUNCIONÁRIOS }\end{array}$ & $\begin{array}{c}\text { SALÁRIO } \\
(\mathbf{R} \$)\end{array}$ & $\begin{array}{c}\text { CUSTO TOTAL * } \\
(\text { R\$) }\end{array}$ \\
\hline Auxiliar Administrativo & 1 & 724,00 & 951,63 \\
Gerente da Empresa & 1 & 1086,00 & 1427,44 \\
Gerente de Produção & 1 & 1086,00 & 1427,44 \\
Auxiliar de Produção & 2 & 724,00 & 1903,26 \\
\hline TOTAL & & 5709,77 \\
* salário + encargos & \multicolumn{3}{c}{}
\end{tabular}

Deverá ser acrescentado também o gasto com o profissional de contabilidade responsável pela documentação da empresa. Baseando-se no custo desse serviço oferecido na cidade de Teixeira de Freitas, chegou-se ao valor de um salário mínimo vigente em dezembro de 2013 de R \$ 724,00. Segundo um dos profissionais consultados para esta pesquisa, o valor médio para a legalização da empresa seria em torno de $\mathrm{R} \$$ 1.800,00. A premissa inicial seria de que, em parceria com a prefeitura, os borracheiros e as empresas revendedoras de pneus de Teixeira e região formassem uma cooperativa para colocar o projeto em prática. Nesse caso, a prefeitura municipal ficaria responsável pelo recolhimento semanal dos pneus inservíveis da cidade, e sua entrega até a recicladora. Os borracheiros e revendedoras (de Teixeira de Freitas e região) ficariam responsáveis pela destinação dos pneus inservíveis aos pontos de coleta preestabelecidos, tirando de circulação uma grande quantidade de pneus inservíveis do meio ambiente.

Tabela 5 - Custos e despesas mensais envolvidos

\begin{tabular}{lc}
\hline CUSTO FIXO & VALORES (R\$) \\
\hline Salários & $5.709,77$ \\
Profissional contábil & 724,00 \\
Água & 115,78 \\
Depreciação (10\%) & $7.250,00$ \\
TOTAL & $13.799,55$ \\
CUSTO SEMIVARIÁVEL & $2.556,57$ \\
Energia Elétrica & 332,98 \\
Telefone & $2.889,55$ \\
TOTAL & \\
CUSTO VARIÁVEL & 0,00 \\
Matéria-prima & 436,19 \\
Big Bag (R $\$ 18,00 /$ ton) & 436,19 \\
\hline TOTAL & Fonte: elaborada pelos autores com base nos dados da pesquisa (2014).
\end{tabular}


A quantidade produzida foi calculada levando-se em consideração o tempo de vida útil média de um pneu. Segundo a Instrução Normativa $n^{\circ} 8$ do IBAMA (2002), os pesos considerados para os pneus inservíveis serão os apontados na Tabela 6 .

Tabela 6 - Pesos dos pneus inservíveis por categoria de veículos

\begin{tabular}{|c|c|}
\hline TIPO DE VEÍCULO & PESO MÉDIO (kg) \\
\hline Motocicleta & 2,50 \\
\hline Automóveis & 5,00 \\
\hline Caminhão e ônibus & 40,00 \\
\hline
\end{tabular}

Fonte: IBAMA (2002).

Para os cálculos das receitas obtidas com a venda dos produtos extraídos da reciclagem dos pneus, considerou-se um total de borracha de $79 \%, 20 \%$ de aço e $1 \%$ de náilon e sujeiras. Considerando os números médios de aumento da frota por ano, obteve-se a média de matéria-prima disponível e a receita bruta por ano, conforme Tabelas 7 e 8 .

Tabela 7 - Média anual de matéria-prima

\begin{tabular}{ccccccc}
\hline \multicolumn{2}{c}{ VEÍ́CULO } & QUANTIDADE & PESO & BORRACHA & AÇO \\
TIPO & $\begin{array}{c}\text { TOTAL } \\
*\end{array}$ & DENEUS & TOTAL & $\begin{array}{c}\text { SUJEIRA } \\
\text { E NYLON } \\
(\mathbf{1 \% )}\end{array}$ \\
\hline Automóvel & 5.650 & 22.600 & 113.000 & 89.270 & 22.600 & 1.130 \\
Caminhão & 465 & 4.653 & 186.100 & 147.019 & 37.220 & 1.861 \\
Ônibus & 148 & 885 & 35.400 & 27.966 & 7.080 & 354 \\
Motocicleta & 6.719 & 13.438 & 33.594 & 26.539 & 6.719 & 336 \\
\hline TOTAL & 12.982 & 41.576 & 368.094 & 290.794 & 73.619 & 3.681 \\
\hline
\end{tabular}

*TOTAL $=$ Total de veículos para troca em 2014.

Fonte: elaborada pelos autores com base nos dados da pesquisa (2014).

Tabela 8 - Previsão de receita bruta anual

\begin{tabular}{lccc}
\hline \multicolumn{1}{c}{ VARIÁVEIS } & $\begin{array}{c}\text { PREÇO MÉDIO DE } \\
\text { VENDA POR Kg } \\
\text { (R\$) }\end{array}$ & $\begin{array}{c}\text { QUANTIDADE } \\
\text { PRODUZIDA } \\
\text { (kg/ano) }\end{array}$ & $\begin{array}{c}\text { TOTAL } \\
\text { (R\$) }\end{array}$ \\
\hline Granulado de borracha (79\%) & 0,80 & 290.794 & $232.635,20$ \\
Fragmentos de aço (20\%) & 0,30 & 73.619 & $22.085,70$ \\
Náilon e sujeiras (1\%) & 0,00 & 3.681 & $\mathrm{R} \$ 0,00$ \\
\hline TOTAL & & 368.094 & $254.720,90$ \\
\hline
\end{tabular}

Fonte: elaborada pelos autores com base nos dados da pesquisa (2014). 
A receita bruta anual prevista será de $\mathrm{R} \$ 254.720,90$, com uma média mensal de $\mathrm{R} \$ 21.226,74$.

Segundo o manual Negócio Certo Sebrae (2011), Crepaldi (2006) e Cassarotto Filho (2002), alguns indicadores servem para verificar a viabilidade financeira do empreendimento, indicando a saúde financeira do negócio e oferecendo uma resposta clara sobre as possibilidades de sucesso do novo empreendimento. Entre esses indicadores, utilizou-se para verificar a viabilidade financeira da usina:

a) Lucratividade: indica em qual percentual é o ganho do negócio sobre o trabalho que se desenvolve.

$$
\begin{aligned}
& L=\left(L L \cdot R T^{-1}\right) \cdot 100 \\
& L=\left(R \$ 4 \cdot 101,45 \cdot R \$ 21 \cdot 226,74^{-1}\right) \cdot 100 \\
& L=19,32 \% \text { a. } m .
\end{aligned}
$$

Em que:

$\mathrm{L}=$ Lucratividade;

LL = Lucro Líquido;

$\mathrm{RT}=$ Receita Total.

Segundo os cálculos, o percentual de ganho do negócio sobre o trabalho desenvolvido é de $19,32 \%$ ao mês.

b) Rentabilidade: apresenta em qual velocidade o capital investido retornará e pode ser estimada pela equação a seguir:

$$
\begin{aligned}
& R=\left(L L . I T^{-1}\right) \cdot 100 \\
& R=\left(R \$ 49 \cdot 217,40 . R \$ 1.635 \cdot 434,15^{-1}\right) \cdot 100 \\
& R=3,00 \% \text { a.a. }
\end{aligned}
$$

Em que:

$\mathrm{R}=$ Rentabilidade;

LL = Lucro Líquido;

IT = Investimento Total.

A rentabilidade encontrada é de $3,00 \%$ ao ano, que pode ser considerada uma rentabilidade baixa. 
c) Prazo de retorno do investimento: mostra qual é o tempo necessário para que se recupere tudo o que foi investido no negócio:

$$
\begin{aligned}
& P R I=I T \cdot L L^{-1} \\
& P R I=R \$ 1.635 .434,15 . R \$ 49.217,40^{-1} \\
& P R I=33,22 \text { anos. }
\end{aligned}
$$

Em que:

PRI = Prazo de Retorno do Investimento;

IT = Investimento Total;

LL = Lucro Líquido.

O prazo de retorno do investimento, ou seja, o tempo necessário para que se recupere tudo o que foi investido no negócio mostrou-se muito extenso, aproximadamente 34 anos, sem levar em consideração a depreciação dos maquinários e equipamentos.

d) Ponto de equilíbrio: indica o quanto tem que ser vendido para evitar que as receitas sejam menores que as despesas. Neste caso, inicialmente, calcula-se a Margem de Contribuição através da Equação 4, e, por fim, o ponto de equilíbrio através da equação:

$$
\begin{aligned}
& M C=P V U-C V U \\
& M C=R \$ 800,00-R \$ 18,00 \\
& M C=R \$ 782,00
\end{aligned}
$$

Em que:

$$
\begin{aligned}
& \text { MC = Margem de Contribuição; } \\
& \text { PVU = Preço de Venda Unitário; } \\
& \text { CVU = Custo Variável Unitário. }
\end{aligned}
$$

A cotação para o preço de venda foi calculado com base na média do mercado atual, segundo a revendedora de Teixeira de Freitas. Não foi considerada a despesa com energia elétrica e água, devido à dificuldade de rateio desses valores no setor de produção.

$$
\begin{aligned}
& P E=C F \cdot M C^{-1} \\
& P E=R \$ 16.689,10 . R \$ 782,00^{-1} \\
& P E=21,34 t .
\end{aligned}
$$


Em que:

$$
\begin{aligned}
& \mathrm{PE}=\text { Ponto de Equilíbrio; } \\
& \mathrm{CF}=\text { Custo Fixo; } \\
& \mathrm{MC}=\text { Margem de Contribuição. }
\end{aligned}
$$

O ponto de equilíbrio indicou que a empresa precisa vender aproximadamente 22 toneladas do pó de borracha por mês para evitar que as receitas sejam menores que as despesas.

Analisando os cálculos, nota-se que, devido ao alto custo de implantação dessa recicladora, os números não se mostraram muito rentáveis. Porém, poderia ser levada em consideração a possibilidade de parcerias com fabricantes de pneus ou com a própria Associação Nacional de Pneumáticos (ANIP), diminuindo assim o custo de investimento inicial, que é bem alto. Além disso, a instalação de uma usina recicladora de pneus inservíveis na região do extremo sul da Bahia é uma ótima alternativa para os problemas ambientais relacionados aos pneumáticos e também representa um ganho social, pois aumenta a oportunidade de emprego para a região, consequentemente a qualidade de vida dos cidadãos. Para Veiga (2013), a reciclagem deve ser o principal objetivo em um sistema de logística reversa, mesmo sendo uma tarefa difícil de se implementar, e muitas vezes nem tão economicamente viável.

A partir desse contexto, foi possível elaborar a matriz SWOT (Quadro 1). A análise SWOT foi desenvolvida na década de 1960 por Albert Humphrey, e é uma ferramenta de análise para verificar a posição estratégica da empresa no ambiente em questão. SWOT tem origem em quatro palavras: $\mathrm{S}=$ Strenght (Força); $\mathrm{W}=$ Weakness (Fraqueza); $\mathrm{O}=$ Opportunities (Oportunidade); $\mathrm{T}=$ Threats (Ameaças) (SERRA; TORRES; PAVAN, 2004).

Quadro 1 - Matriz SWOT da usina recicladora de pneus inservíveis de Teixeira de

$$
\text { Freitas - BA }
$$

\begin{tabular}{|c|c|}
\hline \multicolumn{1}{|c|}{ FORÇAS } & \multicolumn{1}{c|}{ FRAQUEZAS } \\
$\begin{array}{l}\text { - Será a única usina recicladora de pneus } \\
\text { inservíveis da região. } \\
\text { Contribuição para o desenvolvimento } \\
\text { regional sustentável da região. }\end{array}$ & $\begin{array}{l}\text { Alto custo de investimento. } \\
\text { Prazo longo para o retorno do investimento } \\
\text { inicial. }\end{array}$ \\
\hline $\begin{array}{l}\text { AMEAÇAS } \\
\text { Dificuldade de matéria-prima. }\end{array}$ & - $\begin{array}{l}\text { Conscientização da população a respeito da } \\
\text { importância da destinação correta dos pneus }\end{array}$ \\
\hline
\end{tabular}


- $\quad$ Falta de parcerias (prefeituras e empresas privadas). inservíveis.

- Atuação do poder público em políticas voltadas ao desenvolvimento regional sustentável.

Fonte: elaborado pelos autores com base nos dados da pesquisa (2014).

Rubber Manufacturers Association (2005) afirma que existem algumas estratégias que devem ser levadas em consideração para o sucesso da usina de reciclagem de pneus. Essas estratégicas estão ligadas às orientações gerais para a tomada de decisão em um empreendimento nesse segmento. É importante lembrar que os fabricantes e importadores de pneus são obrigados a dar a destinação adequada aos pneus inservíveis, segundo o Conselho Nacional de Meio Ambiente (CONAMA), através da Resolução n 416 de 2009, sendo estes possíveis parceiros para a recicladora.

\subsubsection{Viabilidade ambiental da recicladora de pneus inservíveis}

Em relação aos aspectos ambientais, a recicladora de pneus seria uma possibilidade de melhoria da logística reversa, contribuindo com a criação de objetivos e metas para redução e eliminação desses inservíveis que seriam encaminhados diretamente para ela, de forma independente do serviço público de limpeza urbana. Além disso, os fabricantes, importadores, distribuidores e comerciantes de pneus estariam cumprindo o que é estabelecido pela Política Nacional de Resíduos Sólidos (BRASIL, 2010), diminuindo o risco de sanção pelo poder público do não cumprimento da lei. Para Shibao, Moori e Santos (2010), cada vez mais tem-se consciência de que os recursos do planeta são finitos, justificando, assim, a importância de estabelecer projetos para o processo de planejamento, implantação e controle eficiente dos resíduos para a sustentabilidade ambiental do planeta.

O licenciamento de uma usina recicladora de pneus inservíveis, segundo a Resolução $\mathrm{n}^{\circ}$ 4.327/2013 do Conselho Estadual do Meio Ambiente da Bahia (CEPRAM), pode ser conseguido mediante alguns procedimentos técnicos necessários, pois refere-se a uma indústria de potencial poluidor médio para baixo. No caso desta pesquisa, a recicladora apenas iria triturar os pneus, sem passá-los por nenhum processo químico com grande potencial poluidor. Sabe-se que os pneus são classificados conforme a NBR 10004/2004 como resíduos de classe II, e os resíduos desse empreendimento seriam apenas fibras têxteis que também se classificam como resíduos de classe II. O que a torna mais poluidora/degradadora seria o consumo de água, para 
todo o processo de limpeza da borracha, mas essa água poderia ser reutilizada, desde que passasse por processos de limpeza e também descartada no meio ambiente, por não apresentar riscos de contaminação do solo. As fibras têxtis oriundas do processo de trituração e limpeza dos pneus inservíveis poderiam ser encaminhadas ao aterro sanitário da cidade, sem custo para o empreendimento, para o tratamento e destinação final adequada, não causando nenhum tipo de impacto ao meio ambiente.

Assim, a recicladora de pneus inservíveis pode ser considerada um empreendimento viável em termos ambientais, mostrando-se uma ótima alternativa para a solução da problemática em relação a essa temática.

\subsubsection{Viabilidade social da recicladora de pneus inservíveis}

Uma usina de reciclagem pode gerar vários benefícios sociais, como benefícios em relação à saúde pública, e também benefícios como a inclusão social das classes menos favorecidas no mercado de trabalho, uma vez que pode contribuir para o emprego através do desenvolvimento de associações e cooperativas, ou mesmo como catadores autônomos. Isso porque apresenta mão de obra necessária para a coleta, separação e transporte do material a ser reciclado até a usina de reciclagem. Pablos e Burnes (2007) afirmam que é de extrema importância a participação dos catadores e associações desse ramo na gestão dos resíduos sólidos.

Em relação à saúde pública, a recicladora vem contribuir diretamente com um problema nacional, que é o número de casos de dengue na Bahia, pois, como dito anteriormente, os pneus ocupam muito espaço físico e são difíceis de comprimir, recolher e eliminar, tornando-se ideais para a reprodução do mosquito Aedes aegypti, conhecido popularmente como "mosquito da dengue", causando mal à saúde humana (UNITED NATIONS ENVIRONMENTAL PROGRAMME, 2010).

Segundo dados da Secretaria de Saúde do Estado da Bahia, até março de 2013, foram notificados 29.363 casos de dengue no estado, o que corresponde a um aumento de 10,45\% em relação ao mesmo período de 2012, quando foram notificados 26.584 casos. O município de Teixeira de Freitas se destaca por apresentar 2.446 casos e, junto com Jequié (2.477), Brumado (1.865), Guanambi (1.804), Feira de Santana (901), Itabuna (746), Barreiras (575), Tanque Novo (531), Paramirim (505) e Seabra (476), concentra $42,18 \%$ dos casos no estado. 
Em relação aos aspectos sociais, uma recicladora de pneus inservíveis é viável socialmente, pois contribui para melhorar a qualidade de vida das pessoas. Com a diminuição dos pneus inservíveis no meio ambiente, tem-se a diminuição da poluição, tornando o ambiente mais agradável e evitando a exposição dos cidadãos expostos a riscos, pois sabe-se que esses pneus podem servir de criadouros de mosquitos transmissores de doenças (GARCIA; ZANETTI-RAMOS, 2004).

\section{Considerações finais}

Nesta pesquisa, foi proposto um modelo de usina de reciclagem de pneus inservíveis em Teixeira de Freitas, na Bahia, como alternativa para minimizar o descarte inadequado de pneus e contribuir para a redução de impactos ambientais, possibilitando um maior desenvolvimento social e econômico no extremo sul do estado. Verificou-se que o gerenciamento reverso dos pneus inservíveis em Teixeira de Freitas mostrou-se ineficiente em relação ao que é estabelecido pela Resolução CONAMA 416/2009.

Com base nos resultados da pesquisa, notou-se um alto custo de investimento para a implantação do modelo de recicladora proposto, e um prazo para retorno desse investimento relativamente longo. Nesse caso, sugerem-se ações de parcerias com a Prefeitura Municipal de Teixeira de Freitas, Bahia, com os fabricantes de pneus ou mesmo com a própria Associação Nacional de Pneumáticos (ANIP), diminuindo assim o custo do investimento inicial, pois os fabricantes e importadores de pneus são obrigados a dar a destinação adequada aos pneus inservíveis, segundo o Conselho Nacional de Meio Ambiente (CONAMA), através da Resolução no 416 de 2009. Para a prefeitura é interessante o cumprimento das diretrizes da Política Nacional dos Resíduos Sólidos regulamentada pela Lei n ${ }^{\circ}$ 12.305, de 2 de agosto de 2010 (BRASIL, 2010).

O importante é que a usina recicladora de pneus inservíveis na região do extremo sul da Bahia apresenta-se como uma alternativa relevante em termos ambientais, diminuindo os impactos ao meio ambiente, e oferecendo benefícios sociais como o aumento da oportunidade de emprego para toda a região e melhoria da qualidade de vida dos cidadãos.

\section{REFERÊNCIAS}

AGUIAR A. M. S.; FURTADO, C. F. C. Aplicação da Logística Reversa nas Revendas de Pneus em Fortaleza. In: XIII SEMEAD Seminário em Administração. 2010. 17p. 
ANIP. ASSOCIAÇÃO NACIONAL DA INDÚTRIA DE PNEUMÁTICO. Produção. 2013. Disponível

em:

$<$ http//anip.com.br? cont=conteúdo\&área=32\&titulo_pagina=Produção $>$. Acesso em: 12 set. 2013.

BRASIL. Conselho Nacional do Meio Ambiente. Resolução n ${ }^{\circ}$ 258, de 26 agosto de 1999. Diário Oficial da União, n. 230, seção 1, p. 39, 1999.

BRASIL. Conselho Nacional do Meio Ambiente. Resolução no 301, de 21 março de 2002. Diário Oficial da União, n. 166, seção 1, p. 120-121, 2002.

BRASIL. Conselho Nacional do Meio Ambiente. Resolução no 416, de 30 setembro de 2009. Diário Oficial da União, n. 188, p. 64-65, 2009.

BRASIL. Congresso Nacional. Lei $n^{\circ} 12.305$, de 2 agosto de 2010. Diário Oficial da União, p. 2, 2010.

CASAROTTO FILHO, Nelson. Projeto de Negócio. São Paulo: Atlas, 2002. 304p.

CEPRAM - CONSELHO ESTADUAL DE MEIO AMBIENTE. Resolução no 4.327, de 31 de outubro de 2013. Salvador, Bahia, 2013.

CHEUNG, W. H.; LEE, V. K. C.; MCKAY, G. Minimizing dioxin emissions from integrated MSW thermal treatment. Environmental Science \& Technology, v. 41, n. 6, p. 2001-2007, 2007.

CREPALDI, S. A. Contabilidade Gerencial. São Paulo: Atlas, 2006. 412p.

CUPE - CUSTO UNITÁRIO PINI DE EDIFICAÇÕES. 2013. Disponível em: $<$ http://guiadaconstrucao.pini.com.br/cupe-salvador-ba-nov-2013/custos-unitarios-pinide-edificacoes-cupe-salvador-ba-nov-2013/720>. Acesso em: 7 fev. 2014.

DEMAJOROVIC, J. Da política tradicional de tratamento do lixo à política de gestão de resíduos sólidos: As novas prioridades. Revista de Administração de Empresa, v. 35, n. 3, p. 88-93, 1995.

DEPARTAMENTO ESTADUAL DE TRÂNSITO DA BAHIA - DETRAN - BA, 2013. Disponível em: <http://www.detran.ba.gov.br/web/guest/estatisticas//document_library_display/m1jC/view/88146>. Acesso em: 16 jan. 2014. 
GARCIA, L. P.; ZANETTI-RAMOS, B. G. Gerenciamento dos resíduos de serviços de saúde: uma questão de biossegurança. Cad. Saúde Pública, v. 20, n. 3, p. 23-40, 2004.

IBAMA. INSTITUTO BRASILEIRO DO MEIO AMBIENTE E DOS RECUROS NATURAIS RENOVÁVEIS. Relatório de Pneumáticos. Dados apresentados no Relatório de Pneumáticos - Resolução Conama no 416/09 do Cadastro Técnico Federal. Brasília: Ibama, 2013.

IBGE. INSTITUTO BRASILEIRO DE GEOGRAFIA E ESTATÍSTICA, 2013. IBGE Cidades@. Disponível em: http://cidades.ibge.gov.br/xtras/perfil.php?lang=\&codmun=293135>. Acesso em: 10 ago. 2013.

LIBERA, F. V. D.; ZANINI, M. A.; ROSSATO, M. V.; GUSE, J. C.; DORR, A. C. Parâmetros operacionais para implantação de uma recicladora de pneus inservíveis em Santa Maria - RS. Revista Eletrônica de Gestão, Educação e Tecnologia Ambiental, v. 6, n. 6, p. 1049-1065, 2012.

MOTTA, F. G. A cadeia de destinação dos pneus inservíveis - o papel da regulação e do desenvolvimento tecnológico. Ambiente \& Sociedade, v. 11, n. 1, p. 167-184, 2008.

NEGÓCIO CERTO SEBRAE - Programa de Autoatendimento - Verificando a Viabilidade do Negócio - Manual etapa 2. Disponível em: <http://diegopiovesan.files.wordpress.com/2011/02/manual2_negociocerto.pdf> . Acesso em: 10 fev. 2014.

NORTH DAKOTA DEPARTMENT OF HEALTH. Guideline 21: scrap tire management. Division of Waste Management, 2011. Disponível em: <http://www.ndhealth.gov/wm>. Acesso em: 30 out 2013.

NOVICKI, R. E. M.; MARTIGNONI, B. N. V. Retortagem de pneus pelo processo petrosix. In: Seminário Nacional Sobre Reuso/Reciclagem de Resíduos Sólidos Industriais, 2000, Paraná. Anais... São Paulo: SMA, 2000.

PABLOS, N. P.; BURNES, E. L. Bien recolectada pero mal tratada: el manejo municipal de la basura em ciudad Obregón Hermosilloy Nogales. Revista de Investigación Científica Estudios Sociales, v.15, n. 3, p. 167-193, 2007. 
RUBBER MANUFACTURERS ASSOCIATION. Considerations for Starting a Scrap Tire Company: A Blueprint for Planning a Business Strategy. Estados Unidos, 2005. 20p.

SERRA, F.; TORRES, M. C. S.; TORRES, A. P. Administração Estratégica: conceitos, roteiro prático, casos. Rio de Janeiro: Reichmann \& Affonso Editores, 2004. $178 \mathrm{p}$.

SHIBAO, F. Y.; MOORI, R. G.; SANTOS, M. R. A logística reversa e a sustentabilidade empresarial. XIII SEMEAD - Seminários em Administração. FEA USP, São Paulo, 2010. 17p.

SPREAFICO, P. I.; BARROS, C. S.; SOUSA, A. M. R.; RIBEIRO, R. M. Diagnóstico da Logística Reversa de Pneus Inservíveis na Região Norte do Ceará. In: III Congresso Nacional de Administração e Ciências Contábeis. Rio de Janeiro: 2012. 15p.

STATE OF OHIO ENVIRONMENTAL PROTECTION AGENCY. What is a scrap tire? $2007 . \quad$ Disponível em: <http://www.epa.ohio.gov/portals/34/document/guidance/gd_642.pdf>. Acesso em: 12 nov. 2013.

UNITED NATIONS ENVIRONMENT PROGRAMME. Revised technical guide lines on environmentally sound management of used tyres. Basel: UNEP, 2010. p. 56.

VEIGA, M. M. Analysis of efficiency of waste reverse logistics for recycling. Waste Management \& Research, p. 26-34, 2013.

XAVIER, L. H.; CORRÊA, H. L. Sistemas de logística reversa: criando cadeias de suprimento sustentáveis. São Paulo: Atlas, 2003. 265p.

Recebimento dos originais: $16 / 11 / 2014$

Aceitação para publicação: 05/08/2015 